Hamilton argued that selection favours individuals assisting others in proportion to genes shared in common, other things being equal. Although a laboratory study ${ }^{11}$ has shown that aiding is directed along lines of genetic relatedness among pigtails reared together, our data are clearly insufficient to demonstrate kin selection. Furthermore, we do not suggest that social preferences would be unaffected by experience; pigtails do prefer a familiar conspecific to an unfamiliar one?. Finally, although our results are based on a single age-class in one species, they do heed us to examine the frequent assumption that recognition of kin requires prior association among relatives.

We thank the members of the Animal Behavior Seminar for helpful discussions, and D. Barash, C. Crockett, W. D. Hamilton, R. Holm, J. Lewis, J. Lockard, G. Orians, G. Ruppenthal, P. Sherman, W. Sawrey and the late R. Lockard for comments. This research was supported in part by NIH grants RR00166 and HD08633.

Received 26 September 1979; accepted 6 March 1980.

1. Michener, G. R. Devl Psychobiol. 7, 375-384 (1974).

2. Beecher, M. D. \& Beecher, 1. M., in preparation.

3. Johnson, V. R. Anim. Behav. 25, 418-428 (1977).

4. Brooke, M. de L. Anim. Behav, 26, 622-629 (1978)

5. Emlen, S. T. Z. Tierpsychol. 28, 241-246 (1971).

6. Krebs, J. R. Ecology 52, 2-22 (1971).

7. Packer, C. Nature 265, 441-443 (1977).

8. Hamilton, W. D. J. theor. Biol, 7, 1-52 (1964)

9. Suomi, S. J., Sackett, G. P. \& Harlow, H. F. Devl Psychol. 3, 326-336 (1970).

10. Salzen, E. A. \& Cornell, J. M. Behavior 30, 44-65 (1968)

11. Massey, A. Behav. Ecol. Sociobiol. 2, 31-40 (1977).

12. Greenberg, L. Science 206, 1095-1097 (1979).

\section{Stimulation of the cerebral cortex in the intact human subject}

\section{P. A. Merton \& H. B. Morton}

The National Hospital, Queen Square, London WC1N 3BG, UK

One of the most fertile methods of investigating the brain is to stimulate a part of it electrically and observe the results. So far, however, use of the method in man has been restricted by the necessity of opening the skull surgically to apply the electrodes. Much could be done, both with healthy subjects and with neurological patients, if it were feasible to stimulate through electrodes on the scalp, although the localization of the stimulus on the cortex will always be much less sharp than with electrodes on the brain surface. In an intact man, however, the brain is protected from electricity by the skull and by the scalp, both of which normally offer considerable resistance. Furthermore, the cerebral cortex does not have a particularly low electrical threshold. It is probably for these reasons (despite an occasional contrary claim ${ }^{1}$ ) that attempts to stimulate the brain by applying stimuli from conventional stimulators to the scalp have been stopped by pain or have otherwise failed. These obstacles have now begun to yield. Recently, it was found that, on stimulating muscles in the human hand ${ }^{2}$ without any special preparation of the skin, the effective resistance fell to low values if brief but very high voltage shocks were used. Applying the same technique to the head, it has now proved possible at the first attempt to stimulate two areas of the human cortex, without undue discomfort.

The stimulating electrodes were ordinary stick-on silver-cup electroencephalogram electrodes of $1 \mathrm{~cm}$ diameter, filled with electrode jelly. For the motor area, one electrode was applied initially over the surface marking of the arm area of the motor cortex and the other $4 \mathrm{~cm}$ in front. To stimulate, a $0.1-\mu \mathrm{F}$ condenser charged to up to $\sim 2,000 \mathrm{~V}$ was discharged through the electrodes using a Morse key. The electrode over the motor area was the positive. A shunt resistance of $100 \Omega$ ensured that the time constant of discharge was less than $10 \mu \mathrm{s}$.

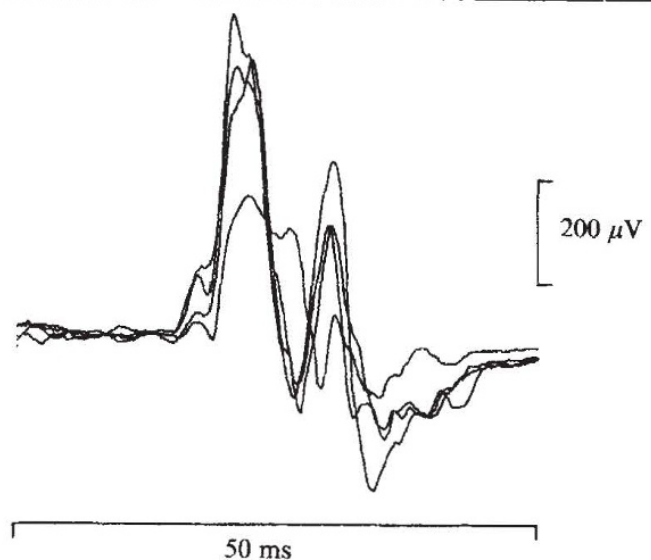

Fig. 1 Stimulation of the arm area of the motor cortex. The records shown are of action potentials from the contracting muscles in the forearm. Stimulation is at the start of the sweep. Four records are superimposed. The latency of responses was $16 \mathrm{~ms}$. (Subject P.A.M.)

Stimulation showed itself by twitch-like movements of the opposite middle and index fingers, or, with the active electrode over the leg area, of the foot. In one subject (height $1.88 \mathrm{~m}$ ), muscle action potentials recorded through surface electrodes over the active muscles showed fairly sharp latencies of $16 \mathrm{~ms}$ for the forearm muscles (Fig. 1) and $34 \mathrm{~ms}$ for the muscles in the lower leg. These values agree with those obtained by stimulating the exposed human motor cortex or the nerve fibres leaving it ${ }^{3,4}$.

With electrodes on the back of the head, over the visual area of the cortex, illusory visual sensations ('phosphenes') were experienced. Larger voltages were necessary for the visual area than for the motor area. For each stimulus the phosphene was very brief. It appeared near the centre of the visual field as a patch, with indefinite edges, subtending some $5^{\circ}$, containing one or a few, sharp, bright sinuous lines. The main evidence that such phosphenes are caused by stimulation of the visual cortex is that they only occurred with electrodes over the visual area and that, within that region, the position of a phosphene in the visual field moved with the position of the stimulating electrodes in a manner that conformed with the known mapping of the visual field on the cortex (half-fields reversed and upside down, with a large area for the centre of the field on the occipital poles). Thus, with a horizontal pair of electrodes above the occipital pole ( $6 \mathrm{~cm}$ above the inion), the phosphene was below the fixation point. It moved upwards roughly to the fixation point when the electrodes were moved downwards (to $3 \mathrm{~cm}$ above the inion). Similarly, the phosphenes appeared mainly on the right with electrodes to the left of the mid-line, and vice versa. They disappeared altogether when the electrodes were moved away more than a few centimetres from the occiput.

Another important observation is that the phosphenes described did not disappear when the eyeballs were pressed on until sight was lost in both eyes, so they were not due to the excitation of the retina by spread of current. Such excitation occurs very readily, as the retina has a low electrical threshold; but the resulting phosphenes fill diffusely much of the visual field, are without structure, are not specially related to stimulation over the visual area, and disappear with pressure-blinding. Thus, although both may be seen simultaneously, phosphenes from current spread to the retina are readily distinguished from the phosphenes we attribute to stimulation of the visual cortex.

Received 6 February; accepted 18 March 1980.

1. Gualtierotti, T. \& Paterson, A. S. J. Physiol., Lond. 125, 278-291 (1954)

2. Hill, D. K., McDonnell, M. J. \& Merton, P. A. J. Physiol, Lond. 300, 2P-3P (1980)

3. Pagni, C. A., Ettore, G., Infuso, L. \& Marossero, F. Experientia 20, 691-692 (1964).

4. Miinner-Brown, S. H., Girvin, J. P. \& Brown, W. F. Can. J. neurol. Sci. 2, 245-253 (1975) 